\title{
Safety Issues of Isolated Probiotic Natured Bacteria from Bangladesh Coastal Waters for Controlling Shrimp Diseases
}

\author{
S. Rahman ${ }^{1}$, S. N. Khan ${ }^{1}$, M. N. Naser ${ }^{2}$, and M. M. Karim ${ }^{1 *}$ \\ ${ }^{1}$ Department of Microbiology, Faculty of Biological Sciences, University of Dhaka, Dhaka 1000, \\ Bangladesh \\ ${ }^{2}$ Department of Zoology, Faculty of Biological Sciences, University of Dhaka, Dhaka 1000, \\ Bangladesh
}

Received 30 May 2011, accepted in final revised form 30 August 2011

\begin{abstract}
The use of chemotherapeutic agents has been questioned for disease management in shrimp aquaculture due to the emergence of drug-resistant bacteria and enduring residual effects in the environments. Instead, microbial interventions in sustainable aquaculture have been proposed, and among them, the use of probiotics as an alternative to antibiotics has gained considerable attention. Earlier, we short-listed nineteen isolates out of ninety six bacteria, isolated from shrimp ghers of coastal areas of Bangladesh that exhibited antagonistic potential against pathogenic vibrios, and non-hemolytic property, presumably indicating their harmless behavior in mammalian system at least in vitro. This prompted us to study their cytotoxic effect in vivo using brine shrimp Artemia franciscana. Six isolates were found having higher lethal values compared with others. Four of them, identified as Pseudomonas and Bacillus spp. exhibited the lowest inhibition against Artemia and were considered safe. Further, in a co-culture experiment it was evident that the isolated probiotic bacteria were shown to outcompete the growth of pathogenic Vibrio harveyi due to their antagonistic properties. The probionts can now therefore be tested in culture environment of Bangladesh in order to understand the effectiveness of microbial control of bacterial diseases in shrimp aquaculture.
\end{abstract}

Keywords: Probiotic bacteria; Food safety; Shrimp aquaculture; Vibrios

(C) 2011 JSR Publications. ISSN: 2070-0237 (Print); 2070-0245 (Online). All rights reserved.

doi:10.3329/jsr.v3i3.7750 J. Sci. Res. 3 (3), 659-668 (2011)

\section{Introduction}

Aquaculture is a fast-growing and rapidly expanding multibillion dollar industry. Marine capture fisheries and aquaculture supplied the world with about 142 million tons of fish in 2008 [1]. Of this total, aquaculture accounted for about 46\%, where shrimp from aquaculture continues to be the most important item traded in terms of value (2.4 million

*Corresponding author: manjur@univdhaka.edu 
tons). Likewise, Bangladesh is no exception that placed this item as the second highest foreign currency earner in her export list. However, the serious concern about this industry is disease. Aquatic animals are constantly and intimately related with the composition and changes in the surrounding environment. The aquatic environment supports their pathogens as well, which can reach densities sufficient to cause disease or to render the animals immunocompromised [2]. A study on penaeid shrimp hatcheries of Cox's Bazar, Bangladesh identified a good number of pathogenic vibrios in the rearing waters [3]. Interestingly enough, pathogenic vibrios have been reported to be liberated once Artemia Cysts of commercial brands, a popular feed for the shrimp commonly used in hatchery operations of Bangladesh are hatched [4]. In addition, overstocking or poor seed conditions contribute significantly to the destruction of "host-pathogen-environment" equilibrium, and ultimately, to disease outbreak.

The use of antibiotics to control diseases was widely practiced and the indiscriminate use of chemotherapeutic agents led to the emergence of numerous antibiotic-resistant bacteria; thereby, the production crashed in many Asian countries [5]. Again Bangladesh is no exception for suffering rejection of more than fifty consignments from EU markets since January 2009 [6] due to the detection of some banned antibiotics in exportable frozen shrimp items. The Government of Bangladesh however took a preemptive measure to avoid any possible sanction by the EU authority by inflicting a self-imposed ban on shrimp export effective from June 1, 2009 that would cost her a loss of Taka 1,500 crore [7]. Control of shrimp diseases with public health safety is therefore the Government's top priority for shrimp and shrimp-based industries.

In this context, microbial intervention can play a vital role in aquaculture production, and effective probiotic treatments may provide broad spectrum and greater nonspecific disease protection [8-11]. By definition, a probiotic should benefit the host either nutritionally or by changing its immediate environment [12] by competitive exclusion of pathogenic bacteria through the production of inhibitory compounds [13]. The range of probiotic microorganisms examined for use in aquaculture includes both Gram-negative and Gram-positive bacteria, bacteriophages, yeasts, and unicellular algae [14].

The selection for probiotic candidate organisms is usually based on in vitro antagonism [13], as well as on the results of adhesion, colonization, and growth in intestinal mucus $[14,15]$. Several other methods of reducing pathogenic microbes in aquaculture, viz., filtration of water, addition of sodium chloride, ozonation, use of ultraviolet light, etc., are also useful but not as much as probiotics. For example, the inhibitory activity of probiotic Bacillus subtilis UTM 126 against Vibrio species conferred protection against vibriosis in juvenile shrimp [16]. The use of probiotic bacteria afterwards produced no disease and the shrimp survival was recorded satisfactory [17]. Therefore, a constant search for new and potent strains as probionts is necessary to combat recently emerged diseases. In an attempt to search probiotic bacteria from the indigenous environment, earlier water samples were collected from the rearing environment of shrimp aquaculture of south-east coastal areas of Bangladesh; and shortlisted nineteen putative probiotic bacteria after screening ninety six bacterial isolates [18]. 
The present study attempts to characterize these isolates to find their safety for shrimp before application in rearing environment of aquaculture.

\section{Methods and Materials}

\subsection{Putative probionts}

This study characterized nineteen bacterial isolates for their safe application in shrimp aquaculture with a view to controlling shrimp diseases after they had been screened by antagonism assay (well diffusion and disc diffusion) and pathogenicity tests from a total of ninety six isolates [18].

\subsection{Target pathogen}

A shrimp pathogen isolated and identified as $V$. harveyi ms1 was used as the target pathogen in this study which has been recovered from samples collected from shrimp hatcheries of Cox's Bazar and Teknaf area [18].

\subsection{Cytotoxicity bioassay}

Brine shrimp cytotoxicity bioassay was performed by applying the cell extracts of putative probionts to the laboratory-cultured brine shrimp (Artemia franciscana), thereafter measuring the toxicity of the agent to kill brine shrimp [19]. The dried cysts of $A$. franciscana were hatched in a conical flask containing $100 \mathrm{ml}$ of sterile seawater under constant aeration at $30^{\circ} \mathrm{C}$ under a continuous light regime to generate two days old live Artemia naupleii. At the same time, the putative probionts were cultured in LB broth containing $1.5 \% \mathrm{NaCl}$ at $30^{\circ} \mathrm{C}$. After a three-day incubation, cell-free supernatant of each isolates were collected by centrifugation at $5000 \mathrm{xg}$ for $15 \mathrm{~min}$. Different concentrations of cell-free supernatant $(100 \%, 50 \%, 25 \%$ and $5 \%)$ were prepared in separate vials diluting with seawater. Four brine shrimp nauplii were drawn through a glass capillary and placed in each vial. The vials were kept in observation for several days at room temperature under the light, and their times of survival were counted. Two vials one with sea water and other with LB broth were taken as control, in addition to another vial containing the extract of a commercial probiotic, Epi B1 (Nature Aqua Technology, India) to validate the test method.

\subsection{Determination of lethality ( $L D_{50}$ values)}

The percentage lethality was determined by comparing the mean surviving larvae of the test and control tubes. $\mathrm{LD}_{50}$ values were obtained by a plot of percentage of the shrimp nauplii killed against the concentration of the extracts and the best-fit line was obtained 
from the data by means of regression analysis. The results of $\mathrm{LD}_{50}$ are expressed for $24 \mathrm{~h}$ observation.

\subsection{Co-culture experiment}

The co-culture method was performed to observe the antagonistic potential of the probionts when grown with the target pathogen, V. harveyi ms1 concurrently [14]. For this purpose, a bacterial population of $10^{8}$ cells, each from the culture broth of the prospective probiont and the target organism were inoculated into $25 \mathrm{ml} \mathrm{LB}$ broth to produce a 1:1 mixed culture. Likewise, different combination of bacterial population at ratios of 1:1, 1:2, $1: 10,1: 100,1: 1,000$ and 1:10,000 of target and the probiotic bacteria respectively were prepared. The co-cultures, made in duplicates were incubated at $30^{\circ} \mathrm{C}$ and samples were withdrawn daily up to four days for the enumeration of vibrio count on TCBS media. After 48 hour incubation, viable plate counts on TCBS media at $10^{-8}$ dilution was done in order to estimate the vibrio count.

\subsection{Identification of the isolates}

The isolates were identified by conventional methods comprising different cultural and biochemical tests. The six isolates selected as putative probionts were cultured in different media and observed their colony morphologies and then subjected to microscopic and biochemical tests, viz, catalase test, oxidase test, motility test, citrate utilization, methyl red test, VP test, arginine dihydrolase, lysine decarboxylase, ornithine decarboxylase test, indole ring test; sucrose, glucose, mannitol and arabinose utilization and gelatinase test for essential identification.

\section{Results}

\subsection{Cytotoxicity bioassay}

The cytotoxicity of nineteen isolated putative probionts was investigated by applying laboratory-cultured brine shrimp (A. franciscana) into cell-free supernatants of probionts, diluted at different concentrations with sterile seawater, ranging from crude supernatant down to $5 \%$. The lesser rate of mortality at higher concentration of the supernatant is better probiont to be effective in the shrimp rearing system, and that was how the interpretation of cytotoxicity was interfered in this study. Fig. 1 shows the regression analysis of the cytotoxicity assay of six probiotic bacteria including the commercial one, Epi B1 that caused less than 50\% brine shrimp mortality at their 5\% concentration. These bacteria included SCT 10P2, SCS 192N, SCT 012C, SCT 013C and SCT 015C, and were broadly acceptable for the application. The isolate, SCT 154B is hereby shown as a representative of the rest fourteen isolates that exhibited Artemia mortality greater than 
$50 \%$ at the $5 \%$ concentration of cell-free supernatants and therefore was considered less suitable for this study.

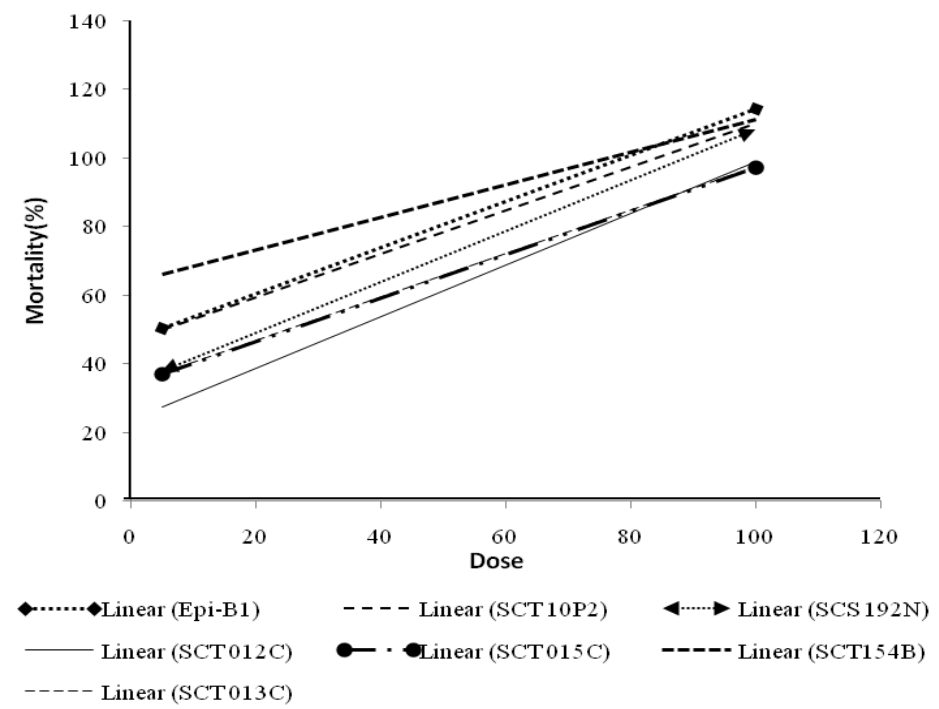

Fig. 1. Regression analysis of the cytotoxicity tests of the six isolated probionts along with the commercial probiont, Epi B1 performed against Artemia franciscana. While X-axis refers to the different concentrations of cell-free supernatant (e.g. 100\%, 50\%, 25\% and 5\%) diluted in sterile seawater, which were applied to four brine shrimp nauplii in each vial, Y-axis illustrates the percentage of mortality of the shrimp nauplii killed as a result of probiont's extracts in 24 hour time, the period when no mortality was recorded in the control vial having only the sterile seawater.

Table 1 summarizes the LD values in three concentrations (25, 50 and 100\%) of the putative probionts calculated from the respective regression equation. The negative $L_{50}$ value of SCT 154B indicates the highest toxic potential of the isolate on brine shrimp. The commercial probiont, Epi B1, however, appears to have more cytotoxic activity than that of the five aforementioned bacterial isolates.

Table 1. LD (lethal dose) values for the probiotic bacteria on brine shrimps.

\begin{tabular}{llrrr}
\hline & & \multicolumn{3}{c}{ Host LD values } \\
\cline { 3 - 5 } Probiont & Regression formula & 25 & 50 & 100 \\
\hline Epi B1 & $Y=0.6733 x+47.203$ & -32.98 & 4.15 & 78.42 \\
SCT 10P2 & $Y=0.6337 x+46.485$ & -33.9 & 5.55 & 84.45 \\
SCS 192N & $Y=0.7426 x+34.084$ & -12.23 & 21.43 & 88.76 \\
SCT 013C & $Y=0.6337 x+33.985$ & -14.18 & 25.27 & 104.17 \\
SCT 012C & $Y=0.7525 x+23.639$ & 1.81 & 35.03 & 101.48 \\
SCT 015C & $Y=0.6337 x+33.985$ & -14.18 & 25.27 & 104.17 \\
SCT 154B & $Y=0.4752 x+63.614$ & -81.26 & -28.65 & 76.57 \\
\hline
\end{tabular}




\subsection{In vivo antagonism assay}

In order to further characterize the antagonistic potential of the isolated probionts directly with the pathogenic $V$. harveyi ms1, an in vivo strategy of co-culture method was applied whereby the pathogen and probiont at their different population ratios were grown concurrently. The co-cultures were incubated at $30^{\circ} \mathrm{C}$ and samples were withdrawn daily up to four days for the enumeration of target organism (vibrio count) on TCBS agar. The probiotic isolates which demonstrated maximum reduction of vibrio count following day 1, preferably at a lower ratio were considered to be the most potential candidate. Accordingly, the isolate SCT 015C exhibited the vibriocidal activity at all ratio tested including the 1:2 (pathogen versus probiotic bacteria) (Fig. 2A), other isolates: SCT 012C, SCT 015C, SCT 10P2 and SCS 192N produced similar kind of results, but were effective from 1:10 ratio (data not shown). A maximum inhibition of vibrio growth was recorded for SCT 012C and SCT 015C, whereas the isolates SCT 10P2 and SCS 192N showed moderate activity against the target $V$. harveyi (Fig. 2B).
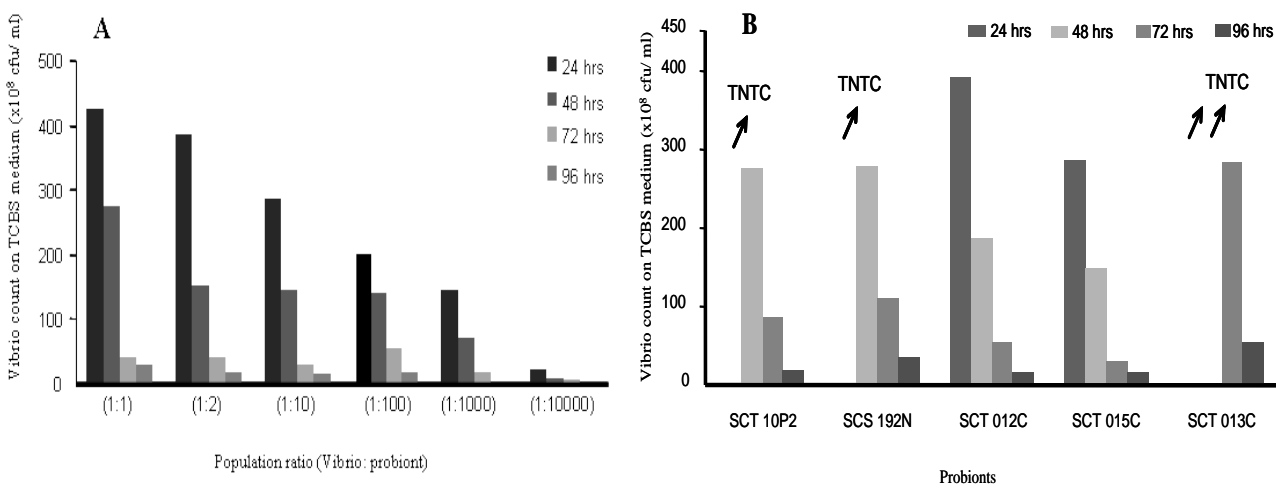

Fig. 2. Co-culture experiments using $V$. harveyi ms1 as a target pathogen and probiotic bacteria at different population ratios (target: probiont). The result is expressed in terms of vibrio count on TCBS agar at a dilution of $10^{-8}$ after daily withdrawn of culture up to four days. A four-day long antagonistic activity of the probiont, SCT 015C applied at its different ratios with target vibrio are shown (A). The vibriocidal activities of other probiotic bacteria, SCT 10P2, SCS 192N, SCT 012C, SCT 015C and SCT 013C at a single ration of 1: 10 over the four days after inoculation are illustrated (B). TNTC refers to Too numerous too count.

\subsection{Identification}

The identification of the isolates was done at least to the genus level based on conventional methods of microscopic, biochemical and cultural analyses followed by the interpretation of the findings according to the Bergey’s Manual of Systemic Bacteriology. Microscopic observation of the isolate SCS 192N exhibited Gram-positive rods arranged in chain form. Further, it grew in Basal media, and hence was identified as Bacillus sp. The rest of the isolates appeared as short rods in single arrangement. Of them, isolates 
SCT 012C, SCT 013C and SCT 015C were identified as Pseudomonas spp. with their growth in selective media: Cetrimide agar and TCBS agar.

Isolate SCT 154B produced characteristic growth pattern in TCBS and did not grow in Cetrimide \& Basal media. It was presumed to be Vibrio sp. when compared with biochemical characteristics. Isolate SCT 10P2 was not identified that produced dubious nature in their properties. However, the identification of six isolated probionts is tabulated below.

Table 2. Identification of the isolated putative probionts.

\begin{tabular}{ll}
\hline Colony ID & Suspected organisms \\
\hline SCT 10P2 & Unidentified \\
SCT 012C & Pseudomonas sp. \\
SCT 013C & Pseudomonas sp. \\
SCT 015C & Pseudomonas sp. \\
SCT 154B & Vibrio sp. \\
SCS 192N & Bacillus sp. \\
\hline
\end{tabular}

\section{Discussion}

The current concern over the spread of genes causing antibiotic resistance due to indiscriminate use of antibiotics in the aquaculture industry, the failure to identify new antibiotics and the inherent problems with developing new vaccines make a compelling case for developing alternative prophylactics. The potential use of probiotics could open new avenue in combating this problem. In fact, the field of probiosis has emerged as a new science with applications in farming and aquaculture as alternatives to antibiotics [2]. To date, no study had been conducted in controlling bacterial infection in shrimps on farms in relation to probiotic usage in Bangladesh. A good number of probiotics, purchased from foreign origin were tested in some hatcheries and culture ponds of Khulna region, and was not found effective [20]. This observation therefore demands to discover new probiotics from the indigenous origin to be effective in local environment.

The present study is a continuation of a previous one [18] that aims to select probiotic bacteria after an initial collection of ninety six environmental strains, isolated from local environment that could be suitable for application in shrimp aquaculture of Bangladesh. The study showed that four of the isolates, SCT 012C, SCT 013C, SCT 015C and SCS 192N identified as Pseudomonas sp. and Bacillus sp., exhibited the lowest cytotoxic activity with ability outcompete the growth of pathogenic vibrios. Together with their non-hemolytic property in mammalian system as revealed earlier [18], the present study selects these four probiotic natured bacteria as safe and hence, are deserved to be tested in rearing culture what could be the future perspective of the present study. 
One of the most important criteria for a candidate to be used in biocontrol is that the organism should be non-pathogenic to the host. The cytotoxicity tests against Brine shrimp (A. franciscana) clearly revealed that the rate of mortality gradually decreased with decreasing concentration of cell-free supernatant of the probiotic bacteria (Figure 1 and Table 1). Since the antimicrobial peptides either released from the whole cells or are applied as cell-free supernatant in the rearing environment, will be heavily diluted, it could be assumed that the cytotoxic effect of the probionts, listed in Table 2, inside animals would be greatly depleted from the estimation obtained, and hence could be considered safe for application.

The growth of pathogenic V. harveyi was controlled by non-pathogenic Bacillus and Pseudomonas species under in vivo (this study) and in vitro [18] conditions. The control of fish and shellfish pathogenic vibrios, particularly using non-pathogenic bacterial strains and disease prevention has received much attention during the last decade [8, 21]. Our coculture experiments showed that the inhibitory activity of the isolates increased with increasing density of the antagonist. A relatively higher concentration of probiont (antagonist) was required to inhibit $V$. harveyi in the co-culture experiments. The present study showed that the antagonist must be present at significantly higher levels, at least by one order of magnitude on an average than the pathogen and the degree of inhibition increased with the level of antagonist (Fig. 2). Therefore, a potential probiotic co-culture must either be supplied on a regular basis or be able to colonize and multiply on or in the host.

The previous study shows that it is possible to change bacterial species composition in large water bodies, hatchery tanks and prawn guts and improve prawn production [22]. Vibrio species might be controlled in this manner. The control of virus disease is more complex than controlling pathogenic bacteria. Fish and shrimp farmers who manage the microbial ecology of their ponds are succeeding in the presence of white spot virus and Vibrio. Our previous study [18] demonstrated that it is not the bacterial cell but an extracellular product of the isolated probionts that is likely to be responsible for vibriocidal activities. Likewise, Vijayan [23] noted that a cell-free culture supernatant of a brackish water isolate, Pseudomonas appeared as a potential antagonistic bacterium against pathogenic vibrios in penaeid and non-penaeid rearing systems. Use of Bacillus species has been particularly useful to displace deleterious bacteria by competitive processes, and thereby found effective in bringing about changes in the microbial species composition in aquaculture ponds [24]. Hence, it can be suggested that the isolates of Bacillus and Pseudomonas species, as discovered from the current study are very significant in terms of their abilities to produce extracellular anti-vibrio component.

Probiotic treatment offers a very promising alternative to the use of antibiotics in fish and shrimp aquaculture. Further study is needed to elucidate the exact mode of action of the observed beneficial effects and to understand the possibilities and limitations of microbial control in aquaculture. 


\section{Acknowledgements}

The authors thankfully acknowledge the financial support extended by Ministry of Science and ICT, Government of the People's Republic of Bangladesh in conducting this study.

\section{References}

1. The State of World Fisheries and Aquaculture, Food and Agriculture Organization (FAO, Rome, Italy, 2010) p. 197.

2. D. J. W. Moriarty, Aquaculture 164, 351 (1998). http://dx.doi.org/10.1016/S0044-8486(98)00199-9

3. S. Rahman, S. N. Khan, M. N. Naser, and M. M. Karim, Asian J. Exp. Bio. Sci. 1 (2), 288 (2010).

4. T. Fahmi, M. M. Karim, S. Rahman, M. N. Naser, and S. N. Khan, Bangladesh J. Zool. 38 (1), 41 (2010).

5. I. Karunasagar, R. Pai, and G. R. Malathi, Aquaculture 128, 203 (1994). http://dx.doi.org/10.1016/0044-8486(94)90309-3

6. The Daily Star internet edition (May 20, 2009).

7. Dept of Fisheries, GoB, Dhaka, Fish Fortnight Issue 2009.

8. S. Rengpipat, S. Rukpratanporn, S. Piyatiratitivorakul, and P. Menasaveta, Aquaculture 191, 271 (2000). http://dx.doi.org/10.1016/S0044-8486(00)00440-3

9. A. Panigrahi and I. S. Azad, Fish Physiol. Biochem. 33, 429 (2007). http://dx.doi.org/10.1007/s10695-007-9160-7

10. A. Sarker, S. N. Khan, M. N. Naser, and M. M. Karim. In: Food Safety and Hygiene. ed. N Choudhury et al. (Bangladesh Academy of Sciences, Bangladesh, 2008) pp. 129-135.

11. A. Sarker, S. Rahman, S. N. Khan, M. N. Naser, and M. M. Karim, Dhaka Uni. J. Pharmaceutical Sci. 9 (1), 23 (2010).

12. A. Kesarcodi-Watson, H. Kaspar, M. J. Lategan, and L. Gibson, Aquaculture 274, 1 (2008). http://dx.doi.org/10.1016/j.aquaculture.2007.11.019

13. L. G. Verschuere, P. Rombaut, Sorgeloos, and W. Verstraete, Microbiol. Mol. Biol. Rev. 64, 655 (2000). http://dx.doi.org/10.1128/MMBR.64.4.655-671.2000

PMid:11104813 PMCid:99008

14. A. Irianto and B. Austin, J. Fish Dis. 25, 633 (2002). http://dx.doi.org/10.1046/j.1365-2761.2002.00422.x

15. N. G. Vine, W. D. Leukes, and H. Kaiser, FEMS Microbiol. Lett. 231, 145 (2004). http://dx.doi.org/10.1016/S0378-1097(03)00954-6

16. H. Josueit,: An Overview on the World Shrimp Market, FAO GlobeFish. (Madrid, Spain, 2004).

17. R. R. Lewis, M. J. Philipps, B. Clough, and D. J. Macintosh, Thematic Review on Coastal Wetland Habitats and Shrimp Aquaculture, World Bank/NACA/WWF/FAO Consortium Program on Shrimp Farming and the Environment (2003).

18. S. Rahman, S. N. Khan, M. N. Naser, and M. M. Karim, J. Bang. Acad. Sci. 33 (1), 139 (2009).

19. A. V. Krishnaraju, T. V. N. Rao, D. Sundararaju, M. Vanisree, H. Tsay, and G. V. Subbaraju, Int. J. App. Sci. Eng. 3 (2), 125 (2005).

20. Dr. M. J. Alam, CSO, Bangladesh Fisheries Research Institute - Personal communication (2009).

21. H. Sugita, Y. Hirose, N. Matsue, and Y. Degudri, Aquaculture 165, 269 (1998). http://dx.doi.org/10.1016/S0044-8486(98)00267-1

22. D. J. W. Moriarty, Disease control in shrimp aquaculture with probiotic bacteria. In: Microbial biosystems; new frontier - Proc. 8th Int. Symp. on Microbial Ecology ed. CR Bell et al. (Atlantic Canada Society for Microbial Ecology, Halifax, Canada, 1999). 


\section{Safety Issues of Isolated Probiotic}

23. K. K. Vijayan, I. S. B. Singh, N. S. Jayaprakash, S. V. Alavandi, S. S. Pai, R. Preetha, J. J. S. Rajan, and T. C. Santiago, Aquaculture 251 (2-4), 192 (2006).

http://dx.doi.org/10.1016/j.aquaculture.2005.10.010

24. H. A. Hong, L. H. Duc, and S. M. Cutting, FEMS Microbiol Rev. 29, 813 (2005).

http://dx.doi.org/10.1016/j.femsre.2004.12.001

PMid:16102604 